\title{
International Talent Cultivation and Scientific and Technological Innovation Platform Construction in Universities of China and Russia
}

\author{
Bailing Gu \\ Heihe University \\ Heilongjiang, China
}

\begin{abstract}
Since the 21st century, the continuous improvement of political relation between China and Russia has made cooperation and communication in science and technology, culture and education become active gradually and deepen ceaselessly. In order to promote continuous development of diplomatic relations between two countries, the communication and cooperation of the two countries need to further expand the scale and deeply develop on communication forms and levels. The medium and long term cooperation development strategy planning between two countries needs international professional talents that know science and technology and are familiar with international conventions. Deepening development of education and scientific research cooperation between universities of the two countries conforms to common interests of economic and cultural development between the two countries. The complementation of China and Russia in education, scientific research and scientific and technological development can lay solid foundation for education and scientific research cooperation. Therefore, it is imperative to promote international talent cultivation in universities of China and Russia through constructing platform for scientific research and innovation.
\end{abstract}

Keywords-scientific and technological cooperation between China and Russia; international talent cultivation; platform for scientific research and innovation

\section{INTRODUCTION}

Nowadays, within international scale, the key to competition of comprehensive national strengthen is competition for innovative talents. Outline of National Medium and Long Term Talent Development Plan (2010-2020) issued by our country in 2010 clearly points out that one of the main tasks to build an innovation-originated nation is to cultivate high level international innovative scientific and technological talents. International innovative talents have two characteristics of "internationalization" and "innovation type". From the perspective of universities, international talents refer to talents with internationalization competence cultivated by university education. It requires universities to make corresponding adjustment in concrete means of cultivation such as teacher, course, course resources, teaching evaluation and management to guide teaching practice. It can be seen that international talents need to have and grasp international knowledge, international rules, international experience and international view in participating in international affairs and competition, and good ability to communicate in cross-cultural communication. ${ }^{1}$ Innovative talent has consciousness of innovation, creative spirit and innovation ability. The premise for growth and development of innovative talents is full and free development of personality.

\section{ANALYSIS ON CONCRETE ENFORCEMENT CONTENTS TO CULTIVATE INTERNATIONAL INNOVATIVE TALENTS}

Talents are important resource and force to drive economic development and social progress. In order to better exert it role, the standard of talent cultivation must meet requirement of social development. In recent years, with continuous strengthening of cooperation and communication between China and Russia in economy, diplomacy, finance, education and technology, the number of international and innovative talents required also reaches historical peak. Therefore, the cultivation of international and innovative talents of universities in China and Russia becomes important factor to promote economic and cultural development in China and Russia. International and innovative talent cultivation of universities in China and Russia can be summarized as five aspects, namely theoretical research on higher education in the world, construction of curriculum and specialty, Sino-foreign cooperation in running schools program and language learning exchange program, strengthening foreign language teaching and promotion of school running in foreign countries, and cultivation of overseas students. Concrete contents analyzed in each aspect are as follows.

\section{A. Theoretical Research on Higher Education in the World}

For international and innovative talent cultivation, theoretical research on higher education in the world is the factor that we need to consider first. Teasing and referring to international talent cultivation pattern in different countries, especially in developed countries can lay thinking foundation and provide practice guidance for concrete implementation of talent cultivation. Universities in China and Russia shall encourage teachers to research on teaching and education internationalization and innovative talent cultivation, make

\footnotetext{
He Wanning. [J]. Economic globalization and internationalization of Higher Education. Journal of Jinan University (Philosophy and Social Sciences), 2001, 23 (3): 20.
} 
information channel unblocked and let relevant teachers have more opportunities to know about contents of international and innovative talent cultivation. If condition permits, universities can set up research institute at school level to carry out oriented research on higher education in China and Russia and let foreign educational theory serve international development of education in our country via these ways.

\section{B. Construction of Curriculum and Specialty}

From the university level, international and innovative talent cultivation also involves construction of curriculum and specialty. From the perspective of internationalization of education and talent cultivation, curriculum reform and construction and implementation of specialty can make universities establish internationalization consciousness of talent cultivation from aspects of management, teacher and student, and have clearer understanding for education positioning. Curriculum construction mainly strengthens the introduction of courses in foreign countries. The introduction of courses in foreign countries shall not be limited to teaching contents. When domestic teachers use original teaching materials to teach courses, they shall also critically absorb advanced experience in foreign countries in aspects such as teaching idea, teaching method and teaching evaluation, which are included in introduction. Universities in China and Russia can also carry out construction of international popular specialties and introduce construction of courses or specialties through teaching in English or Russian.

\section{Sino-Foreign Cooperation in Running Schools Program and Language Learning Exchange Program}

In the process of international and innovative talent training in universities of China and Russia, it is also important to carry out some Sino-foreign cooperation in running schools programs and learning exchange programs of Chinese and Russian, focusing on Chinese students. At present, Chinese and foreign programs in running schools mainly adopt the form that combines domestic learning with foreign learning. In this way, after students' performance meets graduation requirements, they can obtain degrees of two universities at the same time. Besides, universities in two countries should actively promote such programs as credit mutual authentication and joint cultivation of double campus, so that students can study further in foreign partner institutions after completing learning at elementary stage in China, and participate in foreign professional course learning, internship and graduation design ${ }^{2}$. It should be pointed out that construction and training of professional ability and language teaching ability of teachers in Sino-foreign programs in running schools is also of vital importance.

\section{Pay Attention to Foreign Language Teaching and Promote School Running in Foreign Countries}

Another important factor that international and innovative talent cultivation needs to consider is language. Language is the tool for international talents to know about international

\footnotetext{
${ }^{2}$ Liu Xiaoliang. Research on the internationalization of local colleges and
} universities [D]. Dissertation of Northeast Normal University, 2015:58. rules, deal with international relations and affairs as well as communicate and exchange. Universities in China and Russia can intensify international and innovative talent cultivation through strengthening teaching of Chinese and Russian and practically promoting school running in foreign countries. Universities in China and Russia shall vigorously deepen education and teaching reform of foreign language and start with cultivation of students' intercultural communication competence and comprehensive ability in applying foreign language. For example, enlarge international influence of schools and areas that schools are located in through improving school running level of Confucius Institute and expanding the scale of running school, extensively spread Chinese traditional excellent culture, let more Russians learn Chinese and know Chinese culture.

\section{E. Cultivation of Overseas Students}

An important link of international and innovative talent cultivation in universities of China and Russia is to cultivate overseas students. Universities in two countries can adopt various flexible ways, provide multi-layered and various ways of learning according to different standards such as learning time, learning content, learning stage and whether students obtain degree, adopt positive and effective measures to expand recruitment channels, enlarge enrollment scale and vigorously develop education for students with degree. Besides, universities in two countries shall also actively take measures to improve teaching quality and living environment to provide good learning environment and material guarantee for language learning and daily life of overseas students.

\section{TALENT CULTIVATION AND CONSTRUCTION OF PLATFORMS FOR SCIENTIFIC RESEARCH AND INNOVATION OF UNIVERSITIES}

\section{A. Current Situation of International Talent Cultivation of Universities}

At present, from the viewpoint of development status of international talent cultivation in universities of two countries, the contents include international communication and exchange of students, teachers and experts, international promotion of Chinese, holding of China-Russia international academic conferences, cooperation between China and Russia in running schools and international cooperation in scientific research project. However, if we still confine international and innovative talent cultivation to introduction and external assignment of talents on significance of "talent flow", the internationalized process of education in universities of China and Russia will be standstill. Similarly, if universities only focus cultivation and development of international talents on local area, lack international sphere of talent cultivation and position objective of international talent cultivation in narrow field of serving local economy and social development, talents cultivated under this circumstance will lack competitiveness and be replaced in international market. 


\section{B. International Cooperation of Scientific Researches between Universities}

At present, universities in China and Russia realize internationalization of scientific research. Chinese universities cooperate with foreign scientific research institution or friendly universities, establish long-term cooperative relationship, realize sharing of resources and build some research institutes or research and development center together, carry out international joint scientific research projects and promote common progress and improvement of education and scientific research level; in addition, universities in two countries can realize internationalization of scientific research through holding or undertaking international academic conference, international exchange meeting of academic report and international forum; in the internationalization process of scientific research of universities in China and Russia, domestic universities cooperate with foreign friendly universities on levels of college or graduate school, to jointly cultivate graduate students especially doctoral students. The communication is also important in internationalization of scientific research.

\section{Universities of China and Russia Strengthen Construction of Platforms for Scientific Research and Innovation}

Construction of platforms for scientific research and innovation helps to make relationships between universities and scientific research institutions closer. Scientific and technological innovation platform construction of universities between China and Russia plays an important role in accelerating international and innovative talent cultivation and improving scientific research and innovation level on international level. In order to construct scientific and technological innovation platform of universities and scientific research institutions between China and Russia, both sides should strengthen exchange and cooperation in scientific and technological innovation and establish collaborative and efficient new platform for system of scientific and technological innovation with perfect function, diversified forms, distinct gradation, resource sharing ${ }^{3}$.

1) Exert basic function and guiding function of universities: As cradle of knowledge and talents, universities can provide intellectual resources and scientific and technological resources for construction of scientific and technological innovation platform. Universities of China and Russia need to combine subject characteristics and resource superiority of their own, play basic supporting role in construction of platform for scientific research and innovation, design scientific research innovation projects full of regional characteristics and realize joint development and sharing of scientific research and innovation results in universities of two countries. Meanwhile, universities shall fully play important leading role in spreading national language culture, training international innovative talents and promoting scientific and technological innovation, actively develop new

\footnotetext{
${ }^{3}$ Lu Dongjun. Sharing mechanism Construction of science and technology innovation platform of universities and research institutes $[\mathrm{J}]$. Chinese University of science and technology, 2005, (07): 38.
}

projects of humanities and social sciences that can manifest national features as well as ceaselessly drive development of cause and industry of scientific and technological innovation.

2) Construct scientific and technological innovation platforms with diversified forms and perfect function: When universities construct scientific and technological innovation platform, it is necessary to strengthen communication between each other, break the limitation of discipline, unit and region on the basis of analyzing market requirements, establish mechanism of joint development and sharing of scientific and technological innovation platforms, and pay attention to cultivating innovative and interdisciplinary scientific research personnel. Universities shall continuously improve strategic cooperation mechanism of scientific and technological innovation, construct industry-universityresearch platform of diversified forms and perfect function and realize whole process of industry chain of scientific and technological research and development, achievement transformation and business operation, meanwhile, attach importance to carrying out declaration of major scientific research task and tackling the key scientific and technological research project, in order to realize sharing of intellectual resources and scientific and technological resources and winwin of universities between China and Russia. ${ }^{4}$

3) Build diversified joint scientific and technological research innovation model: When constructing platforms for scientific research and innovation, universities of China and Russia need to give full play to superiority in discipline and specialty respectively, complement each other's advantages and create subject groups with new characteristics of scientific research and innovation. Scientific research and innovation platform shall play the role of strengthening communication between universities of two countries, reinforce close relationship, communication and cooperation of universities in personnel, scientific research and academic research and improve enthusiasm of teachers, students and science researchers to participate in scientific and technological innovation through activities of scientific research and innovation; they can also build talent training base with the help of platforms for scientific research and innovation through running schools jointly, accelerate improving training mode of scientific research and innovation talents as well as continuously promote cultivation quality and internationalization level of innovative talents.

\section{CONCLUSION}

Under the background of globalization, bilateral or multilateral scientific and technological cooperation is a shortcut for a country to effectively make use of global scientific and technological innovation resources and accelerate the promotion of core competitiveness of science and technology. China and Russia have very strong

\footnotetext{
${ }^{4}$ Meng Chengmin. Research on the construction of scientific research and innovation platform based on the cultivation of interdisciplinary talents. 2011, (14): 103.
} 
complementation in economic foundation, scientific and technological development as well as cultural development, which lay solid foundation for scientific and technological cooperation. Meanwhile, geopolitical factors between China and Russia also objectively promote mutual beneficial cooperation in scientific and technological innovation. It can be seen that from the perspectives of politics, economy, culture, science and technology as well as geography, the scientific and technological innovation cooperation between China and Russia has broad development space. These favorable conditions make it necessary and inevitable to construct scientific and technological innovation platform. Universities of China and Russia shall improve quality and level of international innovative talent training through construction of scientific and technological innovation platform and provide intellectual support and guarantee for international development of education.

\section{REFERENCES}

[1] Cao Deming. Cultivate International Innovative Talents with Scientific Outlook on Development as Guidance [J], Foreign Language, 2007, (4).

[2] Chen Xinren, Xu Jun. Idea and Connotation of Innovative Foreign Language Talents-Investigation and Analysis [J], Foreign Language World, 2003, (4).

[3] Hu Wenzhong, Sun Youzhong. Highlight Characteristic of Subject, Strengthen Humanistic Education [A], Sun Youzhong. English Education and General Education of Humanity [C], Beijing: Foreign Language Teaching and Research Press, 2008.

[4] Ji Baocheng. Pay Attention to Training of Innovative Personality [J], Truth Seeking, 2006, (24).

[5] Li Weiping. Basic Quality and Training of Innovative Talents (I) [N], China Personnel News, 2006.

[6] Li Zhongyun, Deng Xiuxin. Predicament, Path and Policy Suggestion of Collaborative Innovation in University $[\mathrm{J}]$, China Higher Education, 2011 (17).

[7] Wang Shuguo. Make Concerted Efforts and Collaborative Innovation to Promote Construction of World-class Universities [J], China Higher Education, 2011 (17).

[8] Zhang Li. Strategic Significance and Policy Trend of IndustryUniversity-Research Collaborative Innovation [J], Educational Research, 2011 (17). 